\title{
Scrambled statistics: What are the chances of finding multi-yolk eggs?
}

As a statistical ambassador for the Royal Statistical Society (RSS), I often receive interesting - and sometimes odd - queries from journalists. Since the RSS launched the scheme, my colleagues and I have been asked to comment on a wide variety of things, including the probability of being called for jury service in Scotland and the chances of winning the lottery. One of the more bizarre queries I have received was about the probability of finding an egg with a triple yolk, followed by three eggs with double yolks. From discussion among our group, however, it seems as though variations on this problem pop up quite frequently.

The story I was given concerned a family who lived on a chicken farm, who had gone out and collected eggs from hens that had started laying nine days previously. They were looking for large eggs that they could eat for breakfast. Of the eggs selected, one contained three yolks, and three contained double yolks. The journalist wanted a statistician to confirm that the probability of finding this particular combination of eggs, in this particular order, was 1 in 25 quadrillion (that is, 25 followed by 15 zeros). That figure was based on estimates the journalist had derived from the British Egg Information Service [1], which gave the chances of a double-yolk egg as 1 in 1000, and the chances of a triple-yolker as 1 in 25 million. Multiply the probabilities together $-25000000 \times 1000 \times$ $1000 \times 1000-$ and you get a probability of 1 in 25 quadrillion.

To those with limited experience of statistics, or of chickens, the journalist's calculation might seem reasonable. They are assuming that each of these events is independent and are therefore multiplying their individual probabilities to arrive at an astronomically small chance of finding such a combination of double- and triple-yolkers. However, as so often happens, several details of the story had been overlooked.

Firstly, the eggs that were selected were among the first to be produced by the hens in question, and - based on conversations with my statistical ambassador colleagues - I was led to an article by the BBC's More or Less [2], in which we are told that hens are more likely to lay eggs with multiple yolks for their first eggs compared to their subsequent eggs. Indeed, it seems that the estimated probability of finding a double-yolker decreases sharply for hens that are between 20 and 28 weeks old - from 1 in 1000 to about 1 in 100. There seem to be no good estimates of the relative probability of finding a triple-yolk egg from an older hen, so a conservative estimate may be that young hens are 10 times more likely to produce these sorts of eggs than would be expected in the population at large - but this is unlikely to be correct.

However, as the eggs in our story were from young hens, there was evidence enough to change the probabilities in the journalist's calculation by several orders of magnitude.

The more complex problem was the lack of independence at source. All of the probabilities of finding a multiple-yolk egg assume that you do not have access to your own personal hen farm, as this particular family did. The 1 in 1000 figure is the chance of finding a double-yolk egg if randomly selected from the entire population of eggs. Even then, the probability of finding two double-yolkers in the same store-bought egg carton is not one in a million $(1000 \times 1000)$. Cartons typically consist of eggs from the same flock, and as the hens in a flock are usually all of the same age, according to the BEIS [3], finding two double-yolkers in one box does not qualify as two independent events.

To conclude, then, this particular family had not randomly selected from the entire population of eggs; they had gone out to select large eggs for breakfast from a flock of young hens that they owned. So this specific combination of multi-yolk eggs was rare, yes - but not as rare as it was cracked up to be. 
Sidebar text: How many multi-yolkers should we expect to see? More than 12.2 billion eggs were consumed in the UK in 2015, according to BEIS [4]. Of that total, we would expect to see 488 tripleyolk eggs and more than 12 million double-yolk mckean/Bigstock.com eggs each year

\section{Author Information}

Deirdre Toher is a senior lecturer in applied statistics at the University of the West of England in Bristol, and a statistical ambassador for the Royal Statistical Society

\section{References}

[1] https://www.egginfo.co.uk/ Accessed 6 ${ }^{\text {th }}$ July 2016

[2] http://www.bbc.co.uk/news/magazine-16118149 Accessed 6 th $^{\text {th }}$ July 2016

[3] https://www.egginfo.co.uk/egg-facts-and-figures/faqs\#appearance Accessed 6 th $^{\text {th }}$ July 2016

[4] https://www.egginfo.co.uk/egg-facts-and-figures/industry-information/data Accessed 6th July 2016 